\title{
Erratum: NRF2 regulates serine biosynthesis in non-small cell lung cancer
}

Gina M DeNicola, Pei-Hsuan Chen, Edouard Mullarky, Jessica A Sudderth, Zeping Hu, David Wu, Hao Tang, Yang Xie, John M Asara, Kenneth E Huffman, Ignacio I Wistuba, John D Minna, Ralph J DeBerardinis \& Lewis C Cantley Nat. Genet. 47, 1475-1481 (2015); published online 19 October 2015; corrected after print 15 February 2016

In the version of this article initially published, the colors of the lines in the key in the top right corner of Figure 5h were incorrect. The line labeled "High" should be red and the line labeled "Low" should be blue. The error has been corrected in the HTML and PDF versions of the article.

\section{Erratum: Multisystem Lewy body disease and the other parkinsonian disorders}

J William Langston, Birgitt Schüle, Linda Rees, R Jeremy Nichols \& Carrolee Barlow

Nat. Genet. 47, 1378-1384 (2015); published online 1 December 2015; corrected after print 18 December 2015

In the version of this article initially published, four references were omitted. The error has been corrected in the HTML and PDF versions of the article.

\section{Corrigendum: Germline RECQL mutations are associated with breast cancer susceptibility}

Cezary Cybulski, Jian Carrot-Zhang, Wojciech Kluźniak, Barbara Rivera, Aniruddh Kashyap, Dominika Wokołorczyk, Sylvie Giroux, Javad Nadaf, Nancy Hamel, Shiyu Zhang, Tomasz Huzarski, Jacek Gronwald, Tomasz Byrski, Marek Szwiec, Anna Jakubowska, Helena Rudnicka, Marcin Lener, Bartłomiej Masojć, Patrica N Tonin, Francois Rousseau, Bohdan Górski, Tadeusz Dębniak, Jacek Majewski, Jan Lubiński, William D Foulkes, Steven A Narod \& Mohammad R Akbari Nat. Genet. 47, 643-646 (2015); published online 27 April 2015; corrected after print 12 January 2016

In the version of this article initially published, one of the variants was incorrectly reported as c.634C $>\mathrm{T}$. The correct nomenclature for this variant is c.643C $>\mathrm{T}$. The error has been corrected in the HTML and PDF versions of the article.

\section{Corrigendum: Mutations in the transcriptional repressor REST predispose to Wilms tumor}

Shazia S Mahamdallie, Sandra Hanks, Kristen L Karlin, Anna Zachariou, Elizabeth R Perdeaux, Elise Ruark, Chad A Shaw, Alexander Renwick, Emma Ramsay, Shawn Yost, Anna Elliott, Jillian Birch, Michael Capra, Juliet Gray, Juliet Hale, Judith Kingston, Gill Levitt, Thomas McLean, Eamonn Sheridan, Anthony Renwick, Sheila Seal, Charles Stiller, Neil Sebire, Thomas F Westbrook \& Nazneen Rahman

Nat. Genet. 47, 1471-1474 (2015); published online 9 November 2015; corrected after print 8 February 2016

In the version of this article initially published, the authors failed to acknowledge funding from the NIHR Biomedical Research Centre at Great Ormond Street Hospital for Children NHS Foundation Trust and University College London to Neil Sebire. The error has been corrected in the HTML and PDF versions of the article.

\section{Corrigendum: Fine-mapping cellular QTLs with RASQUAL and ATAC-seq}

Natsuhiko Kumasaka, Andrew J Knights \& Daniel J Gaffney

Nat. Genet. 48, 206-213 (2016); published online 14 December 2015; corrected after print 8 February 2016

In the version of this article initially published, the accession code for the ATAC-seq data was omitted. These data have been deposited in the European Nucleotide Archive under accession ERP011141. The error has been corrected in the HTML and PDF versions of the article. 